\title{
Energy Characteristics of Agricultural Processing Lines \\ ${ }^{1}$ Ershova Irina, ${ }^{2}$ Vasilyev Alexey, ${ }^{3}$ Samarin Gennady, ${ }^{4}$ Tikhomirov Dmitry, ${ }^{5}$ Kudryavtsev Alexander, ${ }^{6}$ Poruchikov Dmitrii, ${ }^{7}$ Ukhanova Viktoria \\ 1,2,3,4,6,7 Federal Scientific Agroengineering Center VIM, Russian Federation, Moscow, 1-y Institutsky proezd, 5 ${ }^{5}$ Scientific and Production Association. S.A. Lavochkin: Khimki 2, Leningradskaya Street \\ Email:eig85@yandex.ru,vasilev-viesh@inbox.ru,samaringn@yandex.ru,tihda@mail.ru,kudralex94@yandex.ru, dv.poruchikov@yandex.ru,v.ukhanova@owen.ru
}

Received: 20th April 2020, Accepted: 05th May 2020, Published: 30th June 2020

\begin{abstract}
Our research objective through the current paper was to develop a methodology for the study of energy-saving lines for processing agricultural products, to justify the parameters and energy-efficient modes of heat and cold supply equipment operation using natural cold, the energy characteristics of the freezing battery, and determine the range of variation of energy flows revenues and expenditures, receipt and processing of information for the development of cooling systems.
\end{abstract}

\section{Keywords}

Energy of Phase Transition Water-Ice, Heat Exchanger, Cold Accumulators, Controlled and Adjustable Processing Parameters, Energy, Material, Time and Operational Characteristics of the Lines, Temporary and Operational Characteristics of Lines, Automated Links, Storage Capacity.

\section{Introduction}

Due to the low technological level of most livestock farms and the lack of modern equipment, the quality of milk produced on farms is still unsatisfactory, and its processing is an energy-intensive and time-consuming process. In Russia as a whole, energy costs for processing 1 ton of milk average $33 \mathrm{kWh}$ [1, 5-13].

The development and implementation of integrated energy-saving equipment and heat and cold supply units using natural cold, which reduce the energy intensity of the agricultural products processing.

\section{Research Objective}

To develop a methodology for the study of energy-saving lines for processing agricultural products, to justify the parameters and energy-efficient modes of heat and cold supply equipment operation using natural cold in order to analyse the energy and material balance of the lines, the energy characteristics of the freezing battery, and determine the range of variation of energy flows revenues and expenditures, receipt and processing of information for the development of flexible cooling systems.

\section{Results and Discussion}

It has been established that the operating time of each link in the production line in the work cycle is a random variable distributed according to a law close to normal [6-13].

The energy flows and the energy balance of an agricultural processing line are analysed. Figure 1 shows the energysaving process line for processing milk for farms using natural cold (Option of heat and cold supply equipment is applied).

Milk through the milk pipe 1 enters the air separator (releaser jar) 2, from where it is pumped through the milk pump 3 and the milk meter 4 to the current milk cooler 5, where it is cooled and enters thermos tanks 6 , from where it is dispensed by the milk pump 3 through the milk counter 4 to the milk tank vehicle. 


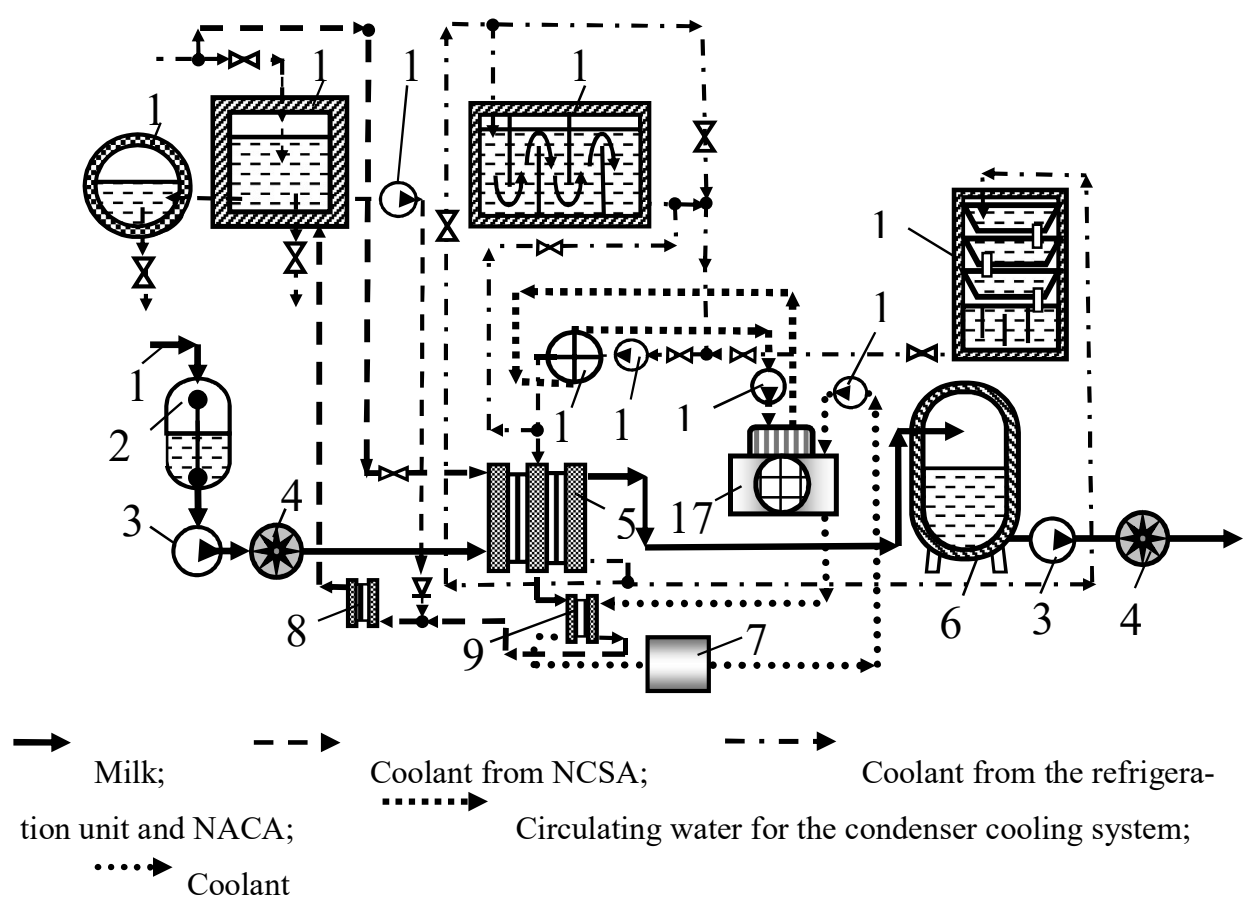

Fig. 1: Automated Energy-Saving Milk Processing Line Using Natural Cold

1 - Milk line; 2 - Milk collector-air separator (releaser jar); 3 - Milk pump; 4 - Milk counter; 5 - Current cooler; 6 - Reservoir-thermos; 7 Capacity for cooling the condenser of the cooling unit; 8.9 - First and second stage heat exchangers; 10 - Warm water reservoir; 11 - Water heater; 12 - Water pump; 13 - Natural and artificial cold accumulator (NACA); 14 - Evaporator of the cooling unit; 15 - Coolant pump; 16 -

Cooling unit compressor; 17 - Condenser of the cooling unit; 18 - Cooling system pump of the cooling unit condenser (cooling tower pump); 19 - Natural cold sectional accumulator (NCSA)

A quantitative assessment of the energy flows of the energy-saving process line considered as a single autonomous system was performed on the basis of the energy balance equation [5-7].

$$
\begin{aligned}
& \sum_{j=}^{M} \sum_{m=1}^{K} \sum_{i=1}^{n}\left(W_{1}, W_{2}, \ldots W_{l}, \ldots, W_{n}\right)= \\
& =\sum_{j=1}^{M} \sum_{m=1}^{K} \sum_{i=1}^{n}\left(W_{1}{ }^{\prime}, W_{2}^{\prime}, \ldots, W_{l^{\prime}}, \ldots, W_{n^{\prime}}\right)+ \\
& \sum_{j=1}^{M} \sum_{m=1}^{K} \sum_{i=1}^{n}\left(W_{1}{ }^{\prime \prime}, W_{2}^{\prime \prime}, \ldots, W_{l^{\prime \prime}}, \ldots, W_{n^{\prime \prime}}\right)
\end{aligned}
$$

Where $W_{l}$ is the amount of energy supplied to the i-th device of the m-th machine of the j-th link; $W_{l}^{\prime}$ - the amount of energy spent by the i-th device of the m-th machine of the j-th link to perform useful work; $W_{l}^{\prime \prime}$ - the amount of energy lost by the $\mathrm{i}$-th device of the $\mathrm{m}$-th machine of the $\mathrm{j}$-th link; $\mathrm{M}$ - the number of $\mathrm{j}$-th links in the process line; $\mathrm{K}$ is the number of the $\mathrm{m}$-th machines in the $\mathrm{j}$-th link of the process line of the $\mathrm{m}$-th machines in the $\mathrm{j}$-th link of the process line; $\mathrm{n}$ is the number of devices consuming energy in the $\mathrm{m}$-th machine.

Thus, the proposed system on farms with pre-cooling of milk from $35^{\circ} \mathrm{C}$ to $15^{\circ} \mathrm{C}$ will allow for the regeneration and use in the process of about $720 \mathrm{kWh}$ electricity that can be used for technological needs [1, 5-13]. 
Table 1: Characteristics and Operating Modes of the Links of Milk Processing Lines Connected to the Central Dairy Point

\begin{tabular}{|c|c|c|c|c|c|c|c|c|c|}
\hline \multirow{3}{*}{$\begin{array}{l}\text { The name of the operating } \\
\text { mechanisms of the process line } \\
\text { links }\end{array}$} & \multicolumn{3}{|c|}{ Typical processing line } & \multicolumn{6}{|c|}{ Process line with energy-saving technology } \\
\hline & \multirow{2}{*}{ Number, pcs. } & Nen, & \multirow{2}{*}{$\begin{array}{l}\text { Tav,man / } \\
\text { day }\end{array}$} & \multirow{2}{*}{ Number, pcs. } & \multirow{2}{*}{\begin{tabular}{l|} 
Nen, \\
$\mathrm{kW}$
\end{tabular}} & \multirow{2}{*}{\begin{tabular}{|l} 
Tav, \\
$\operatorname{man} /$ day \\
\end{tabular}} & \multirow{2}{*}{ Number, pcs. } & \multirow{2}{*}{\begin{tabular}{|l|} 
Nen, \\
$\mathrm{kW}$ \\
\end{tabular}} & \multirow{2}{*}{\begin{tabular}{|l} 
Tav, \\
$\operatorname{man} /$ day \\
\end{tabular}} \\
\hline & & $\mathrm{kW}$ & & & & & & & \\
\hline Air s eparator pump & 4 & 1,1 & 3,5 & 4 & 1,1 & 3,6 & 4 & 1,1 & 3,4 \\
\hline Milk pump & 1 & 1,1 & 4,5 & 1 & 1,1 & 4,5 & 1 & 1,1 & 3,75 \\
\hline Refrigeration compress or & 2 & 15 & 6,0 & 1 & 15,0 & 6,0 & - & - & - \\
\hline Coolant pump & 2 & 1,5 & 6,0 & 1 & 1,5 & 6,0 & 1 & 1,5 & 6,0 \\
\hline Circulating water pump & 2 & 4,0 & 6,0 & - & - & - & - & - & - \\
\hline Cooling tower fan & 2 & 1,5 & 6,0 & - & - & - & - & - & - \\
\hline Thermos tank mixer & 2 & 0,75 & 1,5 & 2 & 0,75 & 1,5 & 2 & 0,75 & 1,5 \\
\hline Milk delivery pump & 1 & 0,75 & 1,5 & 1 & 1,1 & 1,4 & 1 & 1,1 & 0,65 \\
\hline Flushing pump & 1 & 7,5 & 3,0 & 1 & 7,5 & 3,0 & 1 & 7,5 & 3,0 \\
\hline
\end{tabular}

Table 2: Energy Flows of a Process Line with Energy-Saving Technology

\begin{tabular}{|c|c|c|c|c|c|c|c|}
\hline \multicolumn{4}{|c|}{ Warm period } & \multicolumn{4}{|c|}{ Cold period } \\
\hline \multicolumn{2}{|c|}{ Energy input, kWh } & \multicolumn{2}{|c|}{ Energy consumed, $\mathrm{kWh}$} & \multicolumn{2}{|c|}{ Energy input, kWh } & \multicolumn{2}{|c|}{ Energy consumed, kWh } \\
\hline Designation & Value & Designation & Value & Designation & Value & Designation & Value \\
\hline$\Sigma W_{l}$ & 432,92 & $W_{m v}^{\prime \prime}$ & 48,10 & $\Sigma W_{1}$ & 204,65 & $W_{m v}^{\prime \prime}$ & 22,74 \\
\hline & & $W_{m}^{\prime \prime}$ & 60,13 & & & $W_{m}^{\prime \prime}$ & 45,48 \\
\hline$W v$ & 20,4 & $W_{v}^{\prime}$ & $\begin{array}{c}15,84 \\
456\end{array}$ & $W_{v}$ & 19,3 & $W_{v}^{\prime}$ & $\begin{array}{c}15,0 \\
43\end{array}$ \\
\hline$W_{\mathcal{C}}$ & 7,0 & $W_{v}^{\prime \prime}$ & 5,0 & $W$ & 5,5 & $W^{\prime \prime}{ }^{\prime}$ & 4,13 \\
\hline & & $W_{c}^{\prime}$ & 2,0 & $W_{c}$ & & $W_{c}^{\prime}$ & 1,37 \\
\hline$W_{k}$ & 101,7 & $W_{c}^{\prime \prime}$ & 90,0 & $W$ & 11,7 & $W_{c}^{\prime \prime}$ & 9,0 \\
\hline & & $W_{\kappa}^{\prime}$ & 11,7 & $W_{x}$ & & $W_{x}^{\prime}$ & 2,1 \\
\hline$W_{O}$ & 28,0 & $W_{\kappa}^{\prime \prime}$ & $\begin{array}{c}24,0 \\
4,0\end{array}$ & $W_{m}$ & 3,0 & $W_{x}^{\prime \prime}$ & $\begin{array}{l}2,3 \\
07\end{array}$ \\
\hline & 11,1 & $W_{O}^{\prime}$ & 9,0 & & 0,93 & $W_{m}^{\prime}$ & 0,72 \\
\hline$W_{x}$ & & $W^{\prime \prime}$ & 2,1 & $W_{d}$ & & $W_{m}^{\prime \prime}$ & 0,21 \\
\hline & 3,0 & $W^{\prime}$ & 2,3 & & 26,0 & $W^{\prime}$ & 22,5 \\
\hline$W_{m}$ & & ${ }^{m x}$ & 0,7 & $W_{n}$ & 159,56 & $m^{\prime \prime}$ & 3,5 \\
\hline & 2,0 & $W^{\prime \prime} x$ & 1,54 & $W_{5}$ & 258,1 & $W d$ & 46,52 \\
\hline$W_{d}$ & & $W_{m}^{\prime}$ & 0,46 & $W_{6}$ & & $W_{n}^{\prime}$ & 279,12 \\
\hline & 26,0 & $W_{m}^{\prime \prime}$ & 22,5 & $W_{6}$ & 34,98 & $W_{n}^{\prime \prime}$ & 263,43 \\
\hline$W_{n}$ & 201 & $W_{d}^{\prime}$ & 3,5 & $W_{7}$ & & $W_{6}^{\prime \prime}$ & \\
\hline$W_{5}$ & $\begin{array}{l}501,22 \\
253,72\end{array}$ & $W^{\prime \prime} d$ & 46,52 & & & $W^{\prime \prime} 6 \kappa$ & \\
\hline$W_{6}$ & & $W_{n}^{\prime}$ & 279,12 & & & $W^{\prime \prime} t n$ & \\
\hline & 39,36 & $W_{n}^{\prime \prime}$ & 593,34 & & & & \\
\hline$W_{7}$ & & $W^{\prime \prime} 6$ & & & & & \\
\hline & & $\begin{array}{l}W^{\prime \prime} 6 \kappa \\
W^{\prime \prime}{ }^{\prime}\end{array}$ & & & & & \\
\hline
\end{tabular}

For convenience of analysis, the energy balance components (energy flows) are grouped by type of energy received from external sources and spent on technological operations (Fig. 2) [6-13].

The first group includes thermal energy contained in milk, which is supplied to the production line $\Sigma W_{1}$

$\sum W_{1}=\sum W_{1}^{\prime \prime}+W_{A B}^{\prime \prime}$

Where $\sum W_{1}^{\prime \prime}$ - energy losses during milk cooling in pipelines and when it is delivered to a milk tanker vehicle; $W_{a b}^{\prime \prime}$ - milk energy transferred by the coolant to atmospheric air.

The second group $\Sigma \boldsymbol{W}_{\mathbf{2}}$ includes the energy flows of the process line links (air-separation pumps $W v$, transporting $W c, W d$ and mixing pumps $W m$, coolant pumps $W x$ and washing systems $W n$ ), the energy operating modes of which practically do not change for any types of lines throughout the year and do not affect the energy balance 
$\sum W_{2}=\sum W_{2}^{\prime}+\sum W_{2}^{\prime \prime}$

where $\sum W_{2}^{\prime}$ is the energy spent by the links on the technological process: removing milk from the vacuum line $W_{B}^{\prime}$, moving milk through pipelines $W_{c}^{\prime}, W_{\partial}^{\prime}$, stirring it in tanks during storage $W_{\mathcal{M}}^{\prime}$, moving coolant $W_{x}^{\prime}$, moving washing water and solutions through pipelines when washing technological equipment and the system as a whole $W_{n}^{\prime} ; \sum W_{2}^{\prime \prime}=W_{\theta}^{\prime \prime}+W_{c}^{\prime \prime}+W_{\mathcal{M}}^{\prime \prime}+W_{x}^{\prime \prime}$; - energy loss in the process of energy converting from electrical to mechanical type.

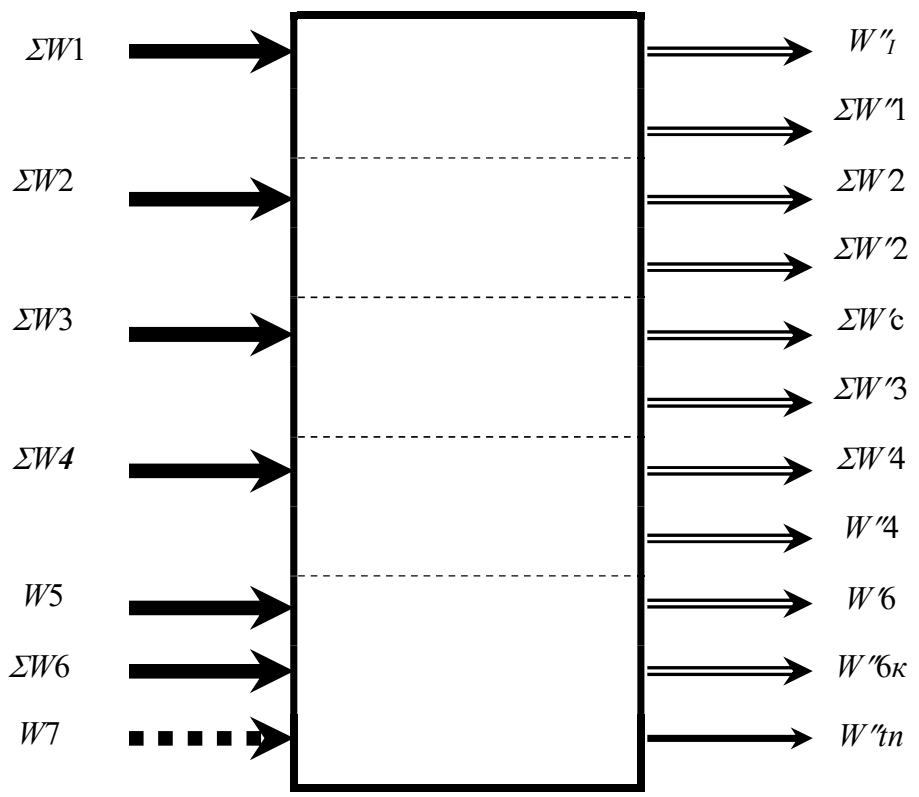

Fig. 2: The Energy Flow Scheme for the Farm Milk Processing Line with Energy-Saving Technology, taking into account the grouping of the Energy Balance Components

The energy flows of the compressor $W \kappa$ and the circulating water pump Wo are allocated into the third group $\Sigma W_{3}$, since their operating mode varies depending on the technology and type of the line during the year and affects the energy balance of the line

$\Sigma W_{3}=\Sigma W_{3}^{\prime}+\Sigma W_{3}^{\prime \prime}$,

where $W^{\prime} 3$ is the energy expended in compressing the coolant vapours $W_{K}^{\prime}$ and moving the circulating water to cool the condenser of the cooling unit $W_{o}^{\prime} ; \Sigma W_{3}^{\prime \prime}=W_{K}^{\prime \prime}+W^{\prime \prime}{ }_{O}$ - energy losses in the process of converting energy from electrical to mechanical type.

The fourth group of energy consumers includes the energy flows $\Sigma W_{4}$ of the cooling tower fans, since a cooling tower is not needed in the production line with energy-saving technology

$\Sigma W_{4}=\Sigma W_{4}^{\prime}+\Sigma W_{4}^{\prime \prime}$,

Where $\Sigma W 44$ is the total energy spent on moving air to cool the water in the tower; $\Sigma W^{\prime \prime} 4$ - energy losses in the process of converting energy from an electrical form to a mechanical one.

The fifth and sixth groups include the energy supplied to the line with water from the $W 5$ farm's water supply sources and the energy spent on heating the water to flush the system $\Sigma W_{6}$

$\Sigma W_{6}=W^{\prime \prime}{ }_{6}+W^{\prime \prime}{ }_{6}$,

Where $W_{6}^{\prime \prime}{ }^{-}$the energy lost when cooling water in pipelines during flushing; $W_{6 \kappa}^{\prime \prime}$ - energy lost during the discharge of waste water into the sewer.

For ease of presentation and further analysis of the energy balance equations for the process line, the individual loss components are grouped by type of energy: electrical and mechanical, lost in the electric motors of pumps and fans

$\Sigma W_{e m 1}^{\prime \prime}=\Sigma W_{2}^{\prime \prime}+\Sigma W_{4}^{\prime \prime}$,

Thermal energy lost with water and milk 
$\Sigma W_{m 1}^{\prime \prime}=W^{\prime \prime}{ }^{\prime}+\Sigma W_{1}^{\prime \prime}+W_{6}^{\prime \prime}+W_{6}^{\prime \prime}$.

As a result, the energy balance equation of a typical production line taking into account expressions (2) ... (8) will have the following form

$\Sigma W_{1}+\Sigma W_{2}+\Sigma W_{3}+\Sigma W_{4}+W_{5}+\Sigma W_{6}=$

$\Sigma W_{2}^{\prime}+\Sigma W_{3}^{\prime}+\Sigma W_{3}^{\prime \prime}+\Sigma W_{4}^{\prime}+\Sigma W^{\prime \prime}{ }_{\ni m 1}+\Sigma W_{m 1}^{\prime \prime}$

An analysis of the components of equation (9) shows that there are reserves for improving the energy characteristics of milk processing lines. These reserves include the use of thermal energy of milk supplied to the processing $\Sigma W_{1}$ (an average of $318 \mathrm{kWh}$ per day). A great reserve is also the use of the natural air and water cold to cool milk. This operation consumes an average of $282 \mathrm{kWh}$ per day, or $\Sigma W_{3}+\Sigma W_{4}$, which is $24 \%$ of the total amount of energy consumed by the line for processing the daily milk yield.

In the cold season, the use of natural cold systems allows us to cool milk without the use of compressors $W k$, circulating water pumps $W o$ and cooling tower fans $W 4$. Therefore, the energy balance equations for the process line with energy-saving technology for the warm and cold seasons will differ significantly.

For the warm season

$\Sigma W_{1}+\Sigma W_{2}+\Sigma W_{3}+W_{5}+\Sigma W_{6}+W_{7}=$

$=\sum W_{2}^{\prime}+\sum W_{3}^{\prime}+\sum W_{3}^{\prime \prime}+\sum W_{\text {эм } 1}^{\prime \prime}+\sum W_{m 1}+\sum W_{m \mu}^{\prime \prime}$,

For the cold season

$\Sigma W_{1}+\Sigma W_{2}+W_{5}+\Sigma W_{6}+W_{7}=$

$=\sum W_{2}^{\prime}+\sum W_{\text {эм } 1}^{\prime \prime}+\sum W_{m 1}^{\prime \prime}+\sum W_{m \mu}^{\prime \prime}$,

Where $W_{7}$ is the regenerated energy for preheating the water used to flush process equipment and the system as a whole; $W^{\prime \prime}{ }_{m}$ - energy of the water used for the technological needs of the farm.

The regenerated heat energy $\Sigma W_{p}$ which is used to heat water for the needs of the farm and flush the system, is determined from the expression

$\Sigma W_{p}=W_{7}+W^{\prime \prime}{ }^{\prime}$,

Required cooling capacity of the cooling unit for production lines with artificial cold accumulators [6-13]

$N_{a h}=T_{f}\left(N_{t e}-Q n\right) / T_{t s}$,

Where $N_{t e}$ is the required cooling capacity of the cooling unit in existing milk cooling systems, $\mathrm{kW}$; $Q n$ is the equivalent cooling capacity of the pre-cooling system, $\mathrm{kW} ; T_{f}$ - the actual operating time of the cooling unit in existing (typical) cooling systems, $\mathrm{h} ; T_{t s}$ - time between milking cycles, hours

A numerical analysis of the energy balance equations shows that due to the use of the milk thermal energy and the coolant condensation heat of the cooling unit, at least $456 \mathrm{kWh}$ used for heating water can be regenerated per day

$\sum W_{p}=W_{7}+W_{m \mu}^{\prime \prime}$.

In a cold season, the use of units that accumulate natural cold for cooling milk on farms located in the latitude of Moscow and to the north allows working without cooling units for $5 \ldots 6$ months a year or more, while saving at least $282 \mathrm{~kW}$ h of electric energy per day

$\Sigma W_{x v}=\left(\Sigma W_{3}+\Sigma W_{4}\right)$.

In a warm season, the energy consumption for milk cooling is reduced by $50 \ldots 65 \%$, and the cooling capacity and installed capacity of cooling units are halved due to its pre-cooling. This saves at least $155 \mathrm{kWh}$ of electricity per day.

$\Sigma W_{m v}=\Sigma W_{3} / 2+\Sigma W_{4}$.

The calculations of the energy balance equation components were carried out using materials from a statistical survey and characteristics of technological equipment for farms according to [5-13], table 1 and table 2. Comparative energy characteristics of the production line with energy-saving technology are presented in table 3. 
Table 3: Energy Flows of an Agricultural Product Processing Line with Energy-saving Technology

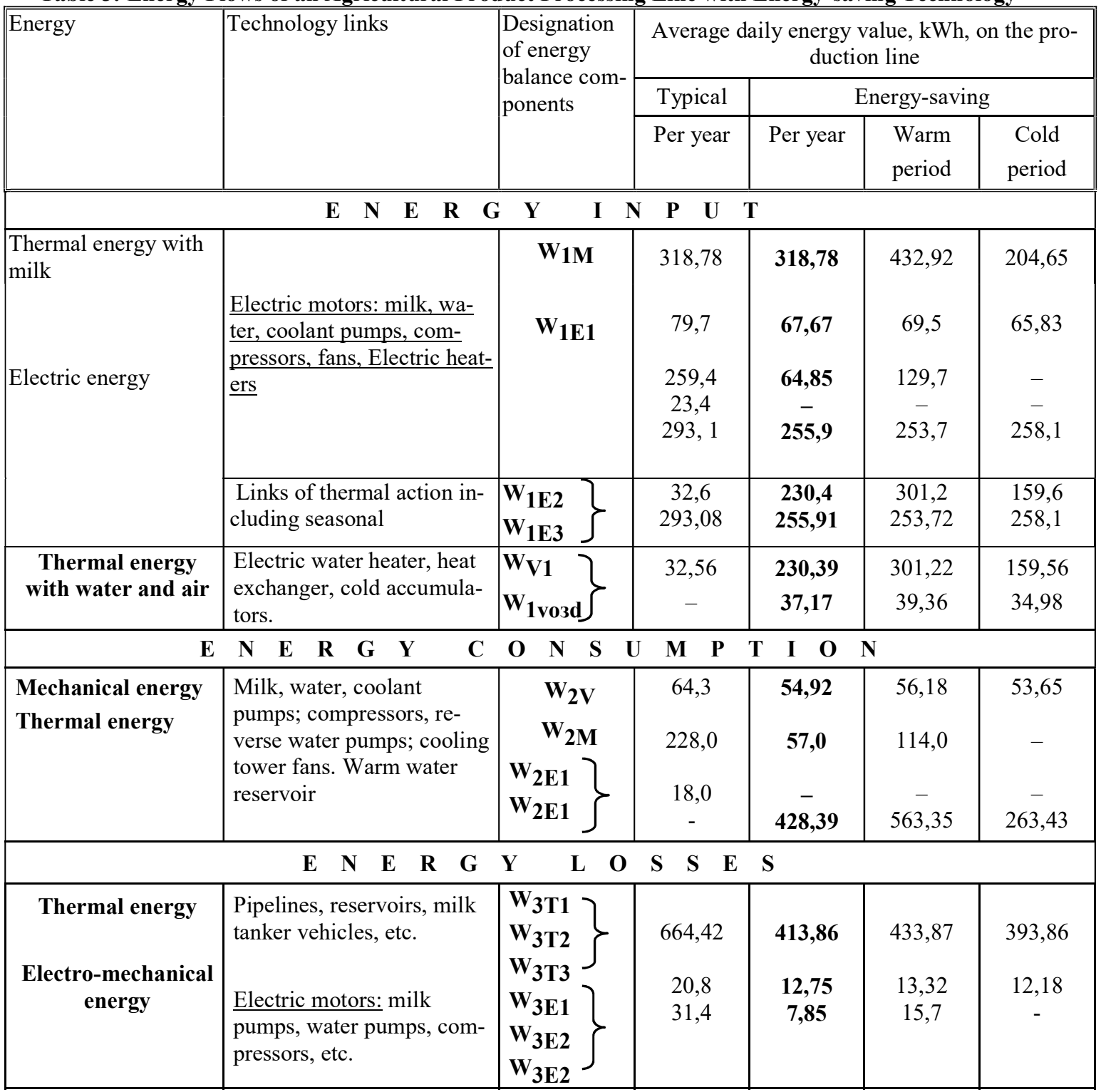




\section{Electric energy saving diagram for cooling agricultural products in various climatic regions of Russia, $\mathrm{kWh} /$ year}

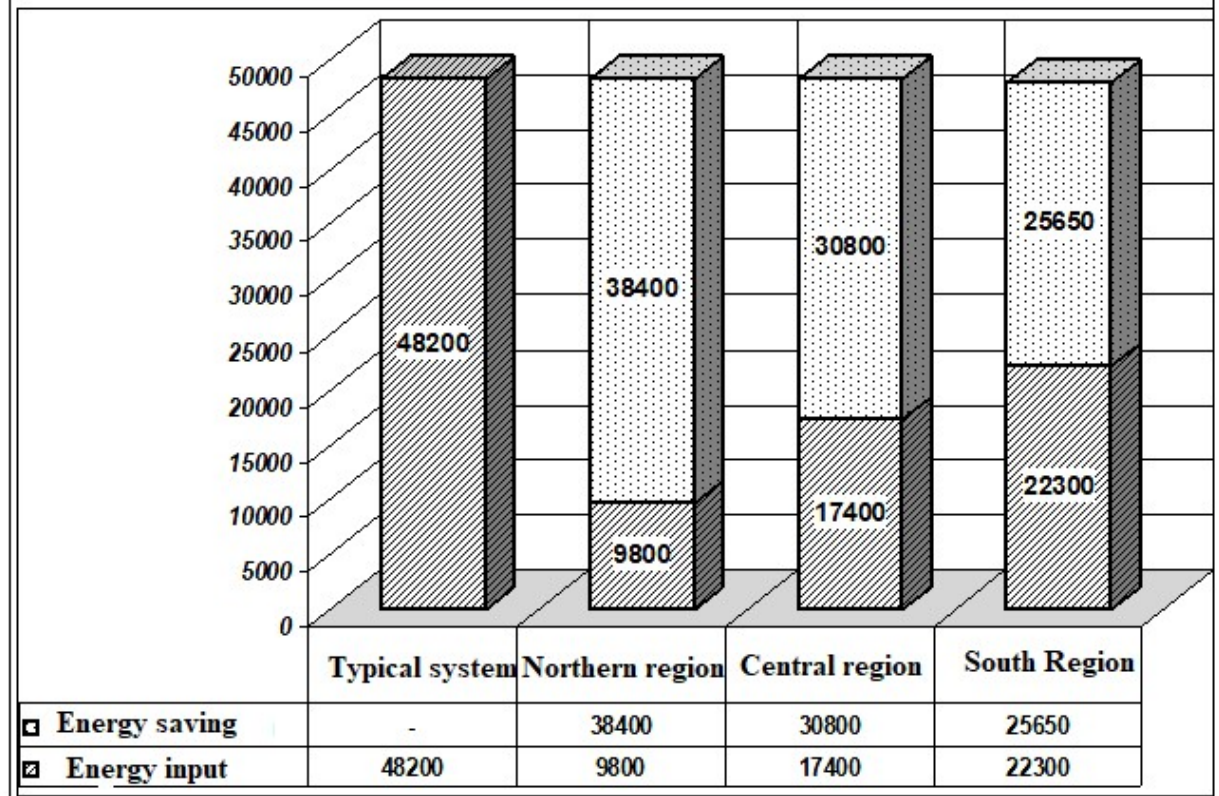

An analysis of energy flows shows that the largest amount of energy when cooling agricultural products using natural cold is saved in the northern region of the country, the minimum amount is in the southern region (see diagram).

\section{Conclusions}

It has been established that due to the cold accumulation and the use of milk thermal energy and the condensation heat of a cooling unit's coolant, a line with energy-saving technology regenerates $600 \mathrm{kWh}$ of energy per day at an average in a warm period, and $290 \mathrm{kWh}$ in a cold period that is used to heat the water that goes to the technological needs of the farm. In addition, in the cold season, the use of only seasonal type units that accumulate natural cold for cooling milk on farms located in the latitude of Moscow and to the north allows working without cooling units for $5 . .6$ months a year or more, which saves not less than $282 \mathrm{kWh}$ of electricity per day. In the warm season, only due to pre-cooling of milk, the energy consumption for cooling is reduced by $50 \ldots 65 \%$, and the cooling capacity and installed capacity of cooling units are $2 \ldots 2.5$ times higher, which saves at least $155 \mathrm{kWh}$ electricity per day. As a result, in the warm season, the energy consumption for cooling 1 ton of milk is $8 \ldots 13$ $\mathrm{kW} \cdot \mathrm{h}$ and $1.8 \ldots 4 \mathrm{~kW} \cdot \mathrm{h}$ in the cold season.

\section{References}

1. Belov, A., A. (2018). Modeling the assessment of factors influencing the process of electro-hydraulic water treatment. VESTNIK NGIEI, 11, 103-112.

2. Sirovatka, V., I. 2014. Improvement of technological processes of manufacturing combic food in economy. Journal of VNIIMZH, 1, 4-11.

3. Vasiliev A.N., Budnikov D.A., Vasiliev A.A. Grain simulation process in the heating module universal electrical microwave field at various algorithms of electrical. In Journal of Agricultural Science Don. 2016. Vol. 1. No. 33. P. 12-17.

4. Dorohov, A., S., Kataev U., V., Ksacnashih, K., A., Skorohodov, D., M. 2018. Quality control of spare parts of agricultural machinery with automated measuring device. Nauka bez granic. Moscow: Avtograf, 2, 44-50.

5. Rodionova, A., V., Borovkov M., S., Ershov, M., A. 2012. Justification of the selected frequency of electromagnetic radiation in physical prophylaxis of harbols. NIVA POVOLZA, 1, 108-110.

6. Ershova, I.G., Belova, M.V., Poruchikov, D.V., Ershov, M.A. 2016. Heat treatment of fat-containing raw materials with energy of electromagnetic radiation. International research journal, № 09(51), 38-40.

7. Belova, M.V., Nonikova, G.V., Ershova, I.G., Ershov, M.A. Mikhailova, O.V. 2016. Innovations in technologies of agricultural raw materials processing. Journal of Engineering and Applied Sciences, Vol. 11, Issue 6, 1269-1277. 
8. Ershova I.G. The economic efficiency of the use of microwave installations for heat treatment of offal / M.V. Belova, I.G. Ershova, N.T. Uyezd // International Scientific, Theoretical and Applied Journal "Bulletin of the Chuvash State Pedagogical University named after I. Y. Yakovlev." - Cheboksary: CSPU, 2013. - No. 4 (80). - P. 30-33.

9. Ershova I., Poruchikov D., Vasiliev A., Samarin G., Ruzhyev V., Zhukov A., Normov D. Technical and economic efficiency assessment of heat pump electric regulator application on agricultural object. International Transaction Journal of Engineering, Management, \& Applied Sciences \& Technologies. - 2019. Vol. 10. No 6. - P. 877-885.

10. Ershova I.G., Uezdny N.T., Naumenko O.V., Novikova G.V. The economic efficiency of the use of microwave installations for baking bakery products // International Scientific, Theoretical and Applied Journal "Bulletin of the Chuvash State Pedagogical University named after I. Ya. Yakovlev." - Cheboksary: CSPU, 2013. - No. 2 (78). - P. 167-170.

11. Uchevatkin A.I. Bogoyavlenskii V.M., Lavrov V.A. Methods of research of technological systems for processing agricultural products as an object of management // FSEI HPE MGAU. M .: Agroengineering. 2007. N1 (21) .C. 48-49.

12. Uchevatkin A.I., Bogoyavlenskii V.M., Lavrov V.A. Control algorithms for discrete-controlled electric drives in the cooling system on technological lines of agricultural processing Products // Vestnik FSEI HPE MGAU. M .: Agroengineering. 2007. N 1 (21). 40-47.

13. Uchevatkin A.I., Bogoyavlenskii V.M., Lavrov V.A. Synthesis of a control system for discrete-controlled electric drives of a cooling system for technological processing lines of agricultural Products // Vestnik FSEI HPE MGAU. M .: Agroengineering, 2007. N 1 (21). 21-25. 